\title{
Vasa nervorum in rat major pelvic ganglion are innervated by nitrergic nerve fibres
}

\author{
Karl A. Beetson ${ }^{1}$, Stephanie F. Smith ${ }^{1,2}$, Asif Muneer $^{3}$, Norman E. Cameron ${ }^{4}$, Mary A. \\ Cotter $^{4}$ \& Selim Cellek ${ }^{1 *}$ \\ ${ }^{1}$ Cranfield Health, Cranfield University, Bedfordshire, MK43 OAL, United Kingdom \\ ${ }^{2}$ School of Clinical Medicine, University of Cambridge, Addenbrooke's Hospital, Cambridge \\ CB2 OSP, United Kingdom \\ ${ }^{3}$ Department of Andrology, University College London Hospital, London, NW1 2BU, United \\ Kingdom \\ ${ }^{4}$ School of Medical Sciences, University of Aberdeen, Aberdeen, AB25 2ZD, United Kingdom
}

*Author for correspondence: Dr Selim Cellek, Cranfield Health, Cranfield University, Bedfordshire, MK43 OAL, United Kingdom; s.cellek@cranfield.ac.uk

This is the pre-peer reviewed version of the following article:

Beetson KA, Smith SF, Muneer A, Cameron NE, Cotter MA, Cellek S.

Vasa nervorum in rat major pelvic ganglion are innervated by nitrergic nerve fibers.

J Sex Med. 2013 Dec; 10(12):2967-74. doi: 10.1111/jsm.12313. Epub 2013 Sep 12.

which has been published in final form at http://www.ncbi.nlm.nih.gov/pubmed/24034566

Published by Wiley. This is the Author Accepted Manuscript issued with:

Creative Commons Attribution Non-Commercial License (CC:BY:NC 3.0). 


\begin{abstract}
:
Introduction: The vasa nervorum comprises a network of small diameter blood vessels that provide blood supply to nerves and ganglia. The cell bodies of autonomic nerves innervating the urogenital organs are housed in the major pelvic ganglia (MPG) in rats. The vasa nervorum of rat MPG have not been characterised previously and it is not known whether these blood vessels are innervated by neuronal nitric oxide synthase (nNOS) containing nitrergic nerves.
\end{abstract}

Aim: To characterise the blood vessels in and around the rat MPG and to assess their nitrergic innervation.

Methods: Major pelvic ganglia were obtained from healthy Sprague Dawley rats, fixed in paraformaldehyde, frozen and sectioned using a cryostat. The blood vessels and their nitrergic innervation were assessed with immunohistochemistry using antibodies against alpha-smooth muscle actin (smooth muscle marker), CD31 (endothelial marker), collagen IV (basal membrane marker) and nNOS. The immunofluorescence was imaged using a laser scanning confocal microscope.

Results: The neuronal cell bodies were contained within a capsule in the MPG. Blood vessels were observed within the capsule of the MPG as well as outside the capsule. The blood vessels inside the capsule were CD31-positive capillaries with no smooth muscle staining. Outside the capsule both capillaries and arterioles were observed. The extracapsular arterioles, but not capillaries were innervated by nNOS-positive nerve fibres.

Conclusions: This study, to our knowledge, is the first to demonstrate the blood vessel distribution pattern and their nitrergic innervation in the rat MPG. While similar studies in human pelvic plexus are warranted, these results suggest that the blood flow in the MPG may be regulated by nitrergic nerve fibres and reveal a reciprocal relationship between nerves and blood vessels.

Key words: nitric oxide, autonomic, nNOS, nitrergic, urogenital, erectile dysfunction, lower urinary tract symptoms 


\section{Introduction:}

Neurones, relative to other mammalian cell types, are critically dependent on oxygen and have a high metabolic rate which necessitates a constant supply of nutrients [1]. This demand for oxygen and other nutrients is fulfilled by blood vessels often referred to as the vasa nervorum, the blood vessels that supply the nerves [2]. Although the vasa nervorum of large nerve trunks such as sciatic nerves have been studied previously [3], such studies in ganglia, which hold the neuronal cell bodies of autonomic or sensory nerves, have been limited [4]. One such ganglion is the major pelvic ganglion (MPG) in the rat which holds the neuronal cell bodies of autonomic nerves innervating the urogenital organs $[5,6]$. The MPG has been considered to be the equivalent of the inferior hypogastric plexus or pelvic plexus in humans $[5,6]$. Although the neuronal cell bodies and blood flow in the rat MPG have been studied previously in healthy and diabetic rats $[7,8]$, there has never been any structural study of the vasa nervorum of rat MPG.

Neuronal cell bodies to have a higher oxygen demand compared to the nerve trunks [9]. Therefore it is not surprising to observe the presence of a dense network of small sized blood vessels around ganglia [10]; arterioles and venules of diameters between 20 and 200 $\mu \mathrm{m}$ and capillaries of diameters less than $20 \mu \mathrm{m}$. The tone of these small diameter blood vessels is regulated by factors released from the endothelium lining their lumen as well as the autonomic nerves circumventing their outer wall. These endothelial and autonomic factors include nitric oxide (NO), endothelin, acetylcholine, noradrenaline and several neuropeptides [11]. NO is synthesised by endothelial NO synthase (eNOS) in the endothelial cells of the vasa nervorum [12]. However the expression of neuronal NO synthase (nNOS) in the nerve fibres around the vasa nervorum has yet to be demonstrated.

Nitric oxide released from the vascular endothelium and nitrergic nerve fibres is the most important factor mediating cavernosal and arterial smooth muscle relaxation for penile erections [13]. NO has also been suggested to be involved in micturition, by inhibiting neurotransmission in the urethra [14] as well as regulating the prostate smooth muscle tone and glandular secretory function [15]. NO is delivered to urogenital organs via nitrergic autonomic nerves whose cell bodies are housed in the MPG as mentioned above. These nitrergic neuronal cell bodies in the ganglia and their axons (which partially form the cavernous nerve) have been studied in physiological and pathological conditions such as diabetes [16]. It is also known that nNOS in nitrergic neurons requires relatively high levels of oxygen to generate NO [17] and that the nitrergic neurons are more susceptible to pathological insults such as hypoxia than those nerves which do not express nNOS [18-20]. It is therefore essential to understand how nitrergic neurons are supplied with blood and how this blood flow is regulated. 
We aimed to investigate the small diameter blood vessels (less than $200200 \mu \mathrm{m}$ in diameter) in and around the rat MPG and assess the expression of nNOS expression in the nerve fibres around these blood vessels. 


\section{Materials and Methods:}

\section{Immunohistochemistry and confocal microscopy:}

A total of thirteen male Sprague Dawley (SD) rats with an average body weight of $400-500 \mathrm{~g}$ were killed using carbon dioxide. The bilateral MPG were dissected immediately and fixed in $4 \%$ paraformaldehyde in $0.1 \mathrm{M}$ phosphate buffer for 72 hours at room temperature; were then transferred to $30 \%$ sucrose in $0.1 \mathrm{M}$ phosphate buffer and stored at $4^{\circ} \mathrm{C}$ for 24 hours for dehydration. The tissues were then frozen in Optimal Cutting Temperature (OCT) compound (VWR, UK) in individual plastic specimen moulds (10mm $\times 10 \mathrm{~mm} \times 5 \mathrm{~mm}$; Thermo scientific) at $-80^{\circ} \mathrm{C}$. The tissues were then sectioned using a cryostat (Bright Instruments, model OTF; UK) and Feather ${ }^{\mathrm{TM}}$ type S35 disposable microtome blades (VWR, UK). The thicknesses of the sections were within a range of 15 to $25 \mu \mathrm{m}$. Sections were then transferred on Superfrost Gold Plus glass slides ( $25 \mathrm{~mm} \times 75 \mathrm{~mm} \times 1 \mathrm{~mm}$; Thermo Scientific, UK) and dried for 2 hours at room temperature.

Slides containing tissue section samples were incubated with $5 \%$ donkey serum (Millipore, UK) and $0.1 \%$ Triton X-100 (Fisher, UK) in phosphate buffer saline for 1 hour at room temperature. The slides were then incubated with the primary antibodies (Table 1 ) in PBS overnight at $4^{\circ} \mathrm{C}$. The slides were then washed with PBS containing $0.1 \%$ Triton X-100 three times, and then incubated with secondary antibodies (Table 1) for 2 hours at room temperature. The slides were then washed again with PBS containing $0.1 \%$ Triton X-100 three times and then the sections were covered with coverslips $(25 \mathrm{~mm} \times 60 \mathrm{~mm}$; VWR BDH Prolabo, UK) using mounting fluid (Millipore Light Diagnostics, UK). In double staining experiments, the slides were incubated with the two primary antibodies simultaneously overnight at $4^{\circ} \mathrm{C}$. The secondary antibodies were applied separately with one hour spacing and PBS wash $(3 \mathrm{x})$ between each application.

The immunofluorescence was visualised and the images were captured using a laser scanning confocal microscope (Zeiss, LSM 510 Meta Axiovert 200M, Germany) with LSM 510 software. Excitation and emission wavelengths for fluorescein were $488 \mathrm{~nm}$ and $520 \mathrm{~nm}$ respectively. Rhodamine excitation and emission wavelengths were $561 \mathrm{~nm}$ and $570 \mathrm{~nm}$ respectively. Digital Z-stacks were obtained to construct 3D projections. Adobe Photoshop ${ }^{\mathrm{TM}}$ was utilised to overlay multiple single channel images of identical tissue samples to create a combined image.

\section{Image analysis:}

Measurement of arteriolar diameters: The blood vessel diameters were measured in slides stained with smooth muscle actin (SMA) antibody. The circumference of each positively 
stained blood vessel in three random fields of view in each slide was measured using the linear measurement tool of the LSM software. As the cross sections of the blood vessels were irregular, direct measurement of the diameter was not possible. The diameter was therefore calculated by dividing the circumference with $\pi$; since the circumference of any circle can be calculated using the following formula:

Circumference $=2 \times \pi \times$ radius $=\pi \times$ diameter

Measuring arteriolar density: The number of blood vessels with diameters between 20 and $200 \mu \mathrm{m}$ was counted in slides stained with smooth muscle actin (SMA) antibody. The number of positively stained blood vessels in three random fields of view in each slide was recorded. The field of view was a fixed area with a size of $204 \times 204 \mu \mathrm{m}\left(\sim 42,000 \mu \mathrm{m}^{2}=\right.$ $0.042 \mathrm{~mm}^{2}$ ). The density of the arterioles was then expressed as the number of blood vessels per $\mathrm{mm}^{2}$ as described by Vitullo et al in 1993 [21].

Measuring capillary density: The area occupied by blood vessels with diameters less than 20 $\mu \mathrm{m}$ was measured in slides stained with CD31 antibody. The total visible area of CD31 positive capillaries was measured in three random fields of view in each slide using the linear measurement tool of the LSM software suite. The field of view was a fixed area with a size of $204 \times 204 \mu \mathrm{m}\left(0.042 \mathrm{~mm}^{2}\right)$. The capillary density was then calculated by dividing the measured area of CD31-positive capillaries by the area of the field of view then multiplied by 100 as described by Chantrain et al in 2003 [22]. 


\section{Results:}

The neuronal cell bodies within the MPG were clustered within a capsule as shown with anti-collagen IV antibody staining (Figure 1). Several small diameter blood vessels were observed outside the capsule (Figure 1).

Immunostaining with anti-smooth muscle actin (SMA) antibody has revealed that most of the blood vessels outside the capsule were SMA-positive. No SMA-positive blood vessels could be observed within the capsule (Figure 2). The density of SMA-positive blood vessels was $161.4 \pm 28.3$ per $\mathrm{mm}^{2}$. The average diameter of SMA-positive blood vessels was $44.4 \pm$ $5.8 \mu \mathrm{m}$.

Using CD31 (endothelial cell surface marker) antibody, we observed several blood vessels with less than $20 \mu \mathrm{m}$ diameter within the capsule as well as outside the capsule (Figure 3). The total area covered by intra- and extra-capsular CD31-positive blood vessels with less than $20 \mu \mathrm{m}$ diameter was $12.4 \pm 3.3 \%$. All of the SMA-positive blood vessels were also positive for CD31 (not shown).

SMA-positive blood vessels that have diameters between 20 and $200 \mu \mathrm{m}$ had nNOS-positive nerve fibres circumventing their outer wall (Figure 4). No nNOS-positive nerve fibres could be observed around the SMA-negative blood vessels. 


\section{Discussion:}

Rat MPG is known to house autonomic neuronal cell bodies in clusters surrounded by a capsule [6]. A similar capsular structure has been reported in intramural ganglia of human male urinary bladder neck [23]. It remains to be established whether human pelvic plexus (human equivalent of MPG) has a similar capsular structure.

We have observed that SMA-positive blood vessels were restricted to the extra-capsular space; no SMA-positive blood vessel could be observed within the capsule. Since SMApositive blood vessels were also CD31 positive and their diameters ranged between 20 and $200 \mu \mathrm{m}$, it is safe to assume that they are most likely to be arterioles and venules. The thickness of the smooth muscle layer suggest that most of these blood vessels are likely to be arterioles rather than venules as venules are known to have thinner smooth muscle wall than arterioles. The only blood vessels that could be observed within the capsule were SMAnegative, CD31-positive, with diameters less than $20 \mu \mathrm{m}$ suggesting that they were capillaries. Thus, the data show that arterioles and venules were restricted to extra-capsular space while only capillaries could be found within the capsule. To our knowledge this is the first demonstration of such a blood vessel distribution in any ganglia. It remains to be established whether a similar vascular distribution exists in human ganglia. The implications of this on oxygen and nutrient delivery to neurons also remain to be investigated.

We have observed nNOS-positive nerve fibres around the SMA-positive blood vessels in the extra-capsular space. No nNOS-positive nerves fibres could be observed around the capillaries either within the capsule or in the extra-capsular space. These results suggest that arterioles supplying the rat MPG are innervated by nitrergic nerve fibres. To our knowledge this is the first demonstration of nitrergic innervation of any vasa nervorum. It remains to be established whether a similar nitrergic innervation can be found in the vasa nervorum of human plexus.

We have observed approximately 160 arterioles within an area of $1 \mathrm{~mm}^{2}$ around the rat MPG. To our knowledge the density of arterioles in any ganglia has not been reported previously. In rat brain approximately 16 arterioles per $\mathrm{mm}^{2}$ have been observed [24]. Although our results may suggest that the MPG may be supplied with a higher density of arterioles than the brain, it should be noted that this striking difference could be due to different measurement techniques. The authors [24] used video imaging techniques in live animals to visualise the arterioles on the cortical surface of the brain. A more detailed immunohistochemical approach like the one we have utilised may have yielded a higher density of arterioles, as not all vessels are necessarily perfused at any one time.

Our results suggest that the dense network of arterioles around the rat MPG has both of the NO sources: eNOS in the endothelium and nNOS in the nerve fibres. These results are 
suggestive of a dual NO support for the smooth muscle of the vasa nervorum akin to that observed in other vascular beds such as penile and cavernosal arterioles [13], cerebral blood vessels [25], renal [26] and gastrointestinal [27]. Compared with endothelial NO generation, the nitrergic NO generation is at a distant physical location from NO's principal scavenger red blood cells, which suggest that the amount of NO reaching arteriolar smooth muscle from the nitrergic nerve fibres may be higher than endothelial NO [28]. Nevertheless, dual source of NO may make arterioles more sensitive to phosphodiesterase type 5 (PDE5) inhibitors since the smooth muscle relaxant efficiency of PDE5 inhibitors are known to be dependent on the amount of available endogenous NO [29,30]. This raises the possibility of the use of PDE5 inhibitors to increase blood flow in the vasa nervorum. This is similar to the findings in the vasa nervorum of the sciatic nerve. The function of the sciatic nerve is well known to be highly dependent on its blood flow; in disease states like diabetes the blood flow deterioration precedes neuronal dysfunction [31]. When the blood flow in the vasa nervorum is restored, this is reflected in an improved neuronal function [32]. Indeed, diabetic sciatic nerve dysfunction has been suggested to be ameliorated by PDE5 inhibitors in animal models [33] and patients [34] which has been attributed to improved blood flow. Interestingly we have observed a similar nitrergic innervation around the blood vessels of the rat sciatic nerve (authors' unpublished observations). Although it remains to be established whether the blood flow in the MPG will be affected by PDE5 inhibitors, the recent clinical success of PDE5 inhibitors in ameliorating the lower urinary tract symptoms as well as erectile dysfunction [35] may suggest that increased blood flow to the autonomic nerves and their ganglia by PDE5 inhibitors may be beneficial in improving the autonomic nerve function [36].

Our results suggest that nitrergic nerve fibres are supplying the vasorelaxant NO to the blood vessels which are supplying blood to the nitrergic neurons (Figure 5). To our knowledge such a reciprocal relationship has not been suggested before. Several questions remain to be answered such as where these nitrergic nerve fibres originate from and whether the nitrergic neurons can regulate their own blood flow, a phenomenon that has been observed in the brain [37].

Our previous studies have shown that nitrergic nerve fibres in urogenital, gastrointestinal and cerebrovascular systems undergo a biphasic selective degeneration during diabetes in animal models $[7,16,38]$. These findings have further been confirmed in samples from patients with diabetes $[39,40]$. It may be speculated that the current finding of a reciprocal relationship between nerves and blood vessels may suggest that diabetes-induced nerve dysfunction may not necessarily be solely due to impaired blood flow in the nerves but a more complex neuronal component may be involved which obviously necessitates further investigation. 


\section{Acknowledgements:}

This project was funded by a research grant from the European Society for Sexual Medicine. S.F.S. received vacation scholarships from the Wellcome Trust and British Pharmacological Society. Preliminary results from this work were presented at the $14^{\text {th }}$ and $15^{\text {th }}$ Annual Congresses of the European Society for Sexual Medicine in 2011 and 2012 respectively and at the $2^{\text {nd }}$ Joint Meeting of the British and American Microcirculation Societies in 2012. 
TABLE 1: Details of the antibodies used in the experiments

\begin{tabular}{|c|c|c|c|c|}
\hline $\begin{array}{l}\text { Primary or } \\
\text { secondary }\end{array}$ & Name & Dilution & $\begin{array}{l}\text { Species raised } \\
\text { in }\end{array}$ & $\begin{array}{l}\text { Source and } \\
\text { catalogue } \\
\text { number }\end{array}$ \\
\hline Primary & $\begin{array}{l}\text { Anti-alpha smooth } \\
\text { muscle actin } \\
\text { (SMA) }\end{array}$ & $1 / 2500$ & Mouse & $\begin{array}{l}\text { Sigma Aldrich } \\
\text { A5228 }\end{array}$ \\
\hline Primary & Anti-nNOS & $1 / 2000$ & Sheep & $\begin{array}{l}\text { A gift from } \\
\text { Prof } \\
\text { Garthwaite, } \\
\text { UCL (refs) }\end{array}$ \\
\hline Primary & Anti-CD31 & $1 / 50$ & Rabbit & $\begin{array}{l}\text { Abcam } \\
\text { AB28364 }\end{array}$ \\
\hline Secondary & $\begin{array}{l}\text { Anti-mouse IgG } \\
\text { (rhodamine } \\
\text { conjugated) }\end{array}$ & $1 / 250$ & Donkey & $\begin{array}{l}\text { Millipore } \\
\text { AP192R }\end{array}$ \\
\hline Secondary & $\begin{array}{l}\text { Anti-mouse IgG } \\
\text { (fluorescein } \\
\text { conjugated }\end{array}$ & $1 / 250$ & Donkey & $\begin{array}{l}\text { Millipore } \\
\text { AP192F }\end{array}$ \\
\hline Secondary & $\begin{array}{l}\text { Anti-sheep IgG } \\
\text { (fluorescein } \\
\text { conjugated) }\end{array}$ & $1 / 250$ & Donkey & $\begin{array}{l}\text { Millipore } \\
\text { AP184F }\end{array}$ \\
\hline Secondary & $\begin{array}{l}\text { Anti-rabbit IgG } \\
\text { (fluorescein } \\
\text { conjugated) }\end{array}$ & $1 / 250$ & Donkey & $\begin{array}{l}\text { Millipore } \\
\text { AP182F }\end{array}$ \\
\hline
\end{tabular}




\section{Figure legends:}

Figure 1: Collagen IV immunostaining of a rat MPG. The capsule surrounding the neuronal cell bodies of the ganglion is marked with white arrow heads. One of the neuronal cell bodies within the intra-capsular area is circled with a white marker for clarity purposes. Several small diameter blood vessels stained with green can be observed outside the capsule (extra-capsular area). Scale bar is $50 \mu \mathrm{m}$.

Figure 2: Alpha smooth muscle actin (SMA; green) immunostaining of a rat MPG. The capsule surrounding the neuronal cell bodies of the ganglion is marked with a white line for clarity purposes. Several SMA-positive blood vessels can be observed outside the capsule, blood vessels with more than $100 \mu \mathrm{m}$ diameters are marked with white arrow heads, while blood vessels with diameters between 20 and $100 \mu \mathrm{m}$ are marked with white arrows. Two small diameter SMA-positive blood vessels can be observed within the intra-capsular area, but these were not in the same plane with the neuronal cell bodies, they most probably were part of the capsule over that area. Please note that SMA immunostaining was not observed in any blood vessels with less than $20 \mu \mathrm{m}$ diameter. Scale bar is $50 \mu \mathrm{m}$.

Figure 3: CD31 (endothelial cell surface marker; green) immunostaining of a rat MPG. The capsule surrounding the neuronal cell bodies of the ganglion is marked with a white line for clarity purposes. Several CD31-positive blood vessels can be observed within and outside the capsule. Blood vessels with diameters more than $20 \mu \mathrm{m}$ are marked with white arrow heads. Blood vessels with diameters less than $20 \mu \mathrm{m}$ are marked with white arrows. Please note that all of the CD31-positive blood vessels within the capsule were less than $20 \mu \mathrm{m}$ diameter. Scale bar: $20 \mu \mathrm{m}$.

Figure 4: nNOS immunostaining of blood vessels in rat MPG. A: nNOS-positive (green) nerve fibres (marked with white arrows) can be observed around the cross section of a blood vessel stained with collagen IV antibody (red). The lumen is marked with a white circle. Scale bar is $50 \mu \mathrm{m}$. B: nNOS-positive (green) nerve fibres (marked with white arrow heads) can be observed around the longitudinal axis of a blood vessel stained with SMA antibody (red). Several layers of smooth muscle cells (marked with white arrow) can be observed in the wall of the blood vessel. The lumen is marked with a white circle. Scale bar is $20 \mu \mathrm{m}$.

Figure 5: Schematic representation of the relationship between nitrergic nerve fibres innervating the blood vessels that supply the nitrergic neurons in the rat MPG. The neurons in the MPG are contained within a capsule. The individual axons originating from the neurons form nerve bundles such as cavernous nerve which are destined for urogenital organs like penis and urinary bladder. The results of this study suggest that vasa nervorum outside the capsule are innervated by nNOS-positive nitrergic nerve fibres. It remains to be elucidated where these fibres originate from. 


\section{References}

1. Ames A, III. CNS energy metabolism as related to function. Brain Res Brain Res Rev 2000; 34: 4268.

2. Appenzeller O, Dhital KK, Cowen T, Burnstock G. The nerves to blood vessels supplying blood to nerves: the innervation of vasa nervorum. Brain Res 1984; 304: 383-386.

3. Low P, Kihara M, Cameron N, Cotter M, Poduslo J. Cause and effect of ischaemia in chronic experimental diabetic neuropathy. Diabet Med 1993; 10 Suppl 2: 52S-55S.

4. Kobayashi S, Mwaka ES, Baba H, Takeno K, Miyazaki T, Matsuo H, Uchida K, Meir A. Microvascular system of the lumbar dorsal root ganglia in rats. Part I: a 3D analysis with scanning electron microscopy of vascular corrosion casts. J Neurosurg Spine 2010; 12: 197-202.

5. Tabatai M, Booth AM, de Groat WC. Morphological and electrophysiological properties of pelvic ganglion cells in the rat. Brain Res 1986; 382: 61-70.

6. Dail WG, Evan AP, Eason HR. The major ganglion in the pelvic plexus of the male rat: a histochemical and ultrastructural study. Cell Tissue Res 1975; 159: 49-62.

7. Cellek S, Foxwell NA, Moncada S. Two phases of nitrergic neuropathy in streptozotocin-induced diabetic rats. Diabetes 2003; 52: 2353-2362.

8. Cameron NE, Cotter MA. Impaired corpus cavernosum responses to cavernous nerve stimulation in diabetic rats: effects of treatment with erythropoietin-delta. Autonom Neurosci 2009; 149: 24-25.

9. McManis PG, Schmelzer JD, Zollman PJ, Low PA. Blood flow and autoregulation in somatic and autonomic ganglia. Comparison with sciatic nerve. Brain 1997; 120 ( Pt 3): 445-449.

10. Kobayashi S, Mwaka ES, Baba H, Takeno K, Miyazaki T, Matsuo H, Uchida K, Meir A. Microvascular system of the lumbar dorsal root ganglia in rats. Part I: a 3D analysis with scanning electron microscopy of vascular corrosion casts. J Neurosurg Spine 2010; 12: 197-202.

11. Melikian N, Seddon MD, Casadei B, Chowienczyk PJ, Shah AM. Neuronal nitric oxide synthase and human vascular regulation. Trends Cardiovasc Med 2009; 19: 256-262.

12. Gonzalez-Hernandez T, Rustioni A. Expression of three forms of nitric oxide synthase in peripheral nerve regeneration. J Neurosci Res 1999; 55: 198-207.

13. Saenz dT, I, Angulo J, Cellek S, Gonzalez-Cadavid N, Heaton J, Pickard R, Simonsen U. Physiology of erectile function. J Sex Med 2004; 1: 254-265.

14. Andersson $\mathrm{KE}$, Arner A. Urinary bladder contraction and relaxation: physiology and pathophysiology. Physiol Rev 2004; 84: 935-986.

15. Kedia GT, Uckert S, Jonas U, Kuczyk MA, Burchardt M. The nitric oxide pathway in the human prostate: clinical implications in men with lower urinary tract symptoms. World J Urol 2008; 26: 603609. 
16. Cellek S. Point of NO return for nitrergic nerves in diabetes: a new insight into diabetic complications. Curr Pharm Des 2004; 10: 3683-3695.

17. Stuehr DJ, Santolini J, Wang ZQ, Wei CC, Adak S. Update on mechanism and catalytic regulation in the NO synthases. J Biol Chem 2004; 279: 36167-36170.

18. Benesova $\mathrm{P}$, Langmeier $\mathrm{M}$, Betka J, Trojan $\mathrm{S}$. Changes in the number of nitrergic neurons following kainic acid administration and repeated long-term hypoxia. Physiol Res 2004; 53: 343-349.

19. Benesova $\mathrm{P}$, Langmeier $\mathrm{M}$, Betka J, Trojan S. Long-lasting changes in the density of nitrergic neurons following kainic acid administration and chronic hypoxia. Physiol Res 2005; 54: 565-571.

20. Mbaku EM, Zhang L, Pearce WJ, Duckles SP, Buchholz J. Chronic hypoxia alters the function of NOS nerves in cerebral arteries of near-term fetal and adult sheep. J Appl Physiol 2003; 94: 724-732.

21. Vitullo JC, Penn MS, Rakusan K, Wicker P. Effects of hypertension and aging on coronary arteriolar density. Hypertension 1993; 21: 406-414.

22. Chantrain CF, DeClerck YA, Groshen S, McNamara G. Computerized quantification of tissue vascularization using high-resolution slide scanning of whole tumor sections. J Histochem Cytochem 2003; 51: 151-158.

23. Dixon JS, Jen PY, Gosling JA. A double-label immunohistochemical study of intramural ganglia from the human male urinary bladder neck. J Anat 1997; 190 ( Pt 1): 125-134.

24. Sonntag WE, Lynch CD, Cooney PT, Hutchins PM. Decreases in cerebral microvasculature with age are associated with the decline in growth hormone and insulin-like growth factor 1. Endocrinology 1997; 138: 3515-3520.

25. Toda N, Ayajiki K, Okamura T. Cerebral blood flow regulation by nitric oxide: recent advances. Pharmacol Rev 2009; 61: 62-97.

26. Toda N, Okamura T. Modulation of renal blood flow and vascular tone by neuronal nitric oxide synthase-derived nitric oxide. J Vasc Res 2011; 48: 1-10.

27. Toda N, Okamura T. The pharmacology of nitric oxide in the peripheral nervous system of blood vessels. Pharmacol Rev 2003; 55: 271-324.

28. Kavdia M, Popel AS. Contribution of nNOS- and eNOS-derived NO to microvascular smooth muscle NO exposure. J Appl Physiol 2004; 97: 293-301.

29. Kalsi JS, Ralph DJ, Thomas P, Bellringer J, Minhas S, Kell PD, Cellek S. A nitric oxide-releasing PDE5 inhibitor relaxes human corpus cavernosum in the absence of endogenous nitric oxide. J Sex Med 2005; 2: 53-57.

30. Toque HA, Priviero FB, Teixeira CE, Claudino MA, Baracat JS, Fregonesi A, De NG, Antunes E. Comparative relaxing effects of sildenafil, vardenafil, and tadalafil in human corpus cavernosum: contribution of endogenous nitric oxide release. Urology 2009; 74: 216-221.

31. Cameron NE, Cotter MA, Low PA. Nerve blood flow in early experimental diabetes in rats: relation to conduction deficits. Am J Physiol 1991; 261: E1-E8. 
32. Cameron NE, Cotter MA. Potential therapeutic approaches to the treatment or prevention of diabetic neuropathy: evidence from experimental studies. Diabet Med 1993; 10: 593-605.

33. Wang L, Chopp M, Szalad A, Liu Z, Bolz M, Alvarez FM, Lu M, Zhang L, Cui Y, Zhang RL, Zhang ZG. Phosphodiesterase-5 is a therapeutic target for peripheral neuropathy in diabetic mice. Neuroscience 2011; 193: 399-410.

34. Hackett G. PDE5 inhibitors in diabetic peripheral neuropathy. Int J Clin Pract 2006; 60: 11231126.

35. Porst H, Kim ED, Casabe AR, Mirone V, Secrest RJ, Xu L, Sundin DP, Viktrup L. Efficacy and safety of tadalafil once daily in the treatment of men with lower urinary tract symptoms suggestive of benign prostatic hyperplasia: results of an international randomized, double-blind, placebocontrolled trial. Eur Urol 2011; 60: 1105-1113.

36. Cellek S, Cameron NE, Cotter MA, Muneer A. Pathophysiology of diabetic erectile dysfunction: potential contribution of vasa nervorum and advanced glycation endproducts. Int J Impot Res 2013; 25: $1-6$.

37. Iadecola C, Nedergaard M. Glial regulation of the cerebral microvasculature. Nat Neurosci 2007; 10: 1369-1376.

38. Cellek S, Anderson PN, Foxwell NA. Nitrergic neurodegeneration in cerebral arteries of streptozotocin-induced diabetic rats: a new insight into diabetic stroke. Diabetes 2005; 54: 212-219.

39. Dashwood MR, Crump A, Shi-Wen X, Loesch A. Identification of neuronal nitric oxide synthase (nNOS) in human penis: a potential role of reduced neuronally-derived nitric oxide in erectile dysfunction. Curr Pharm Biotechnol 2011; 12: 1316-1321.

40. Chandrasekharan B, Anitha M, Blatt R, Shahnavaz N, Kooby D, Staley C, Mwangi S, Jones DP, Sitaraman SV, Srinivasan S. Colonic motor dysfunction in human diabetes is associated with enteric neuronal loss and increased oxidative stress. Neurogastroenterol Motil 2011; 23: 131-8, e26. 
FIGURE 1

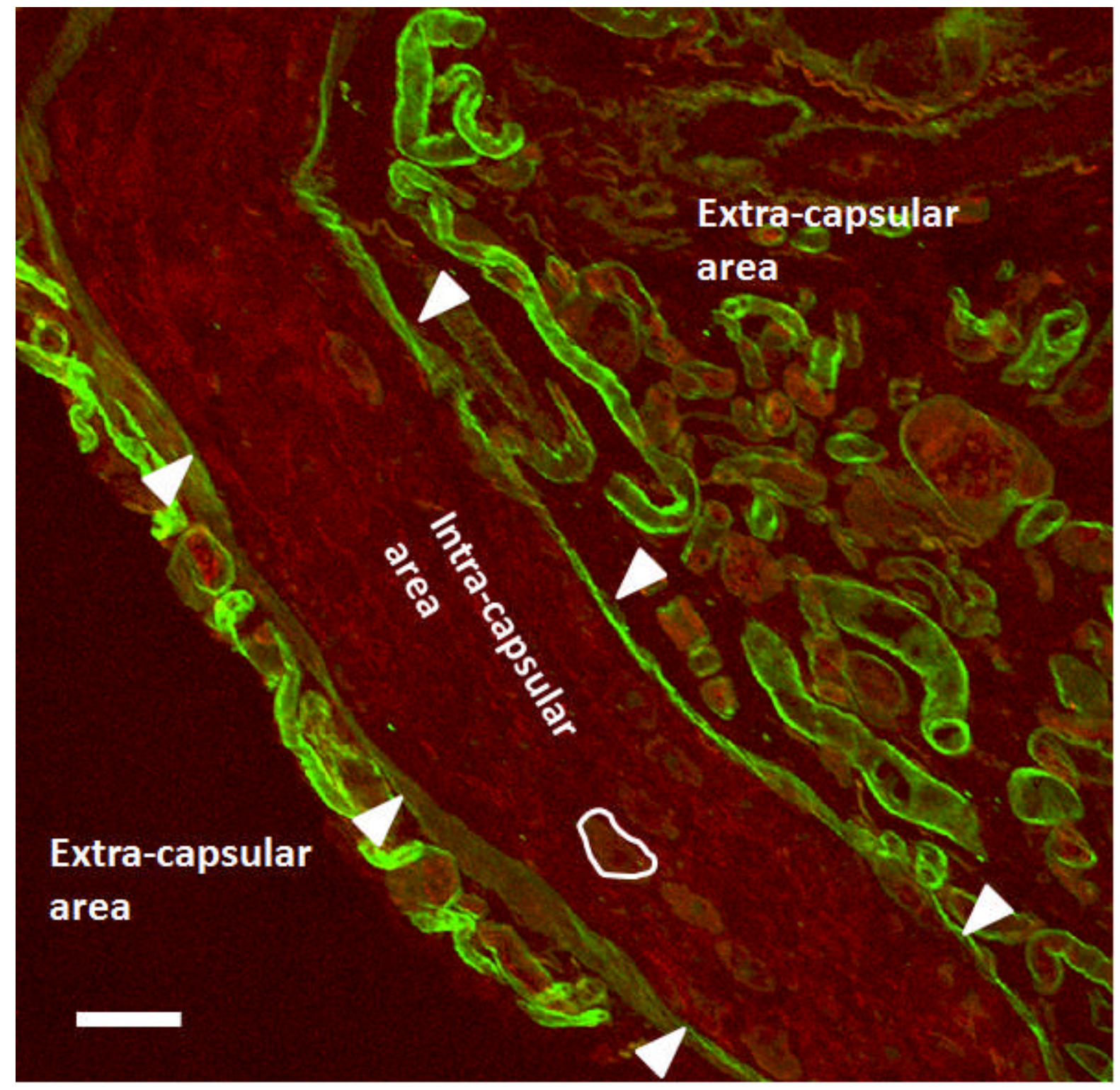


FIGURE 2

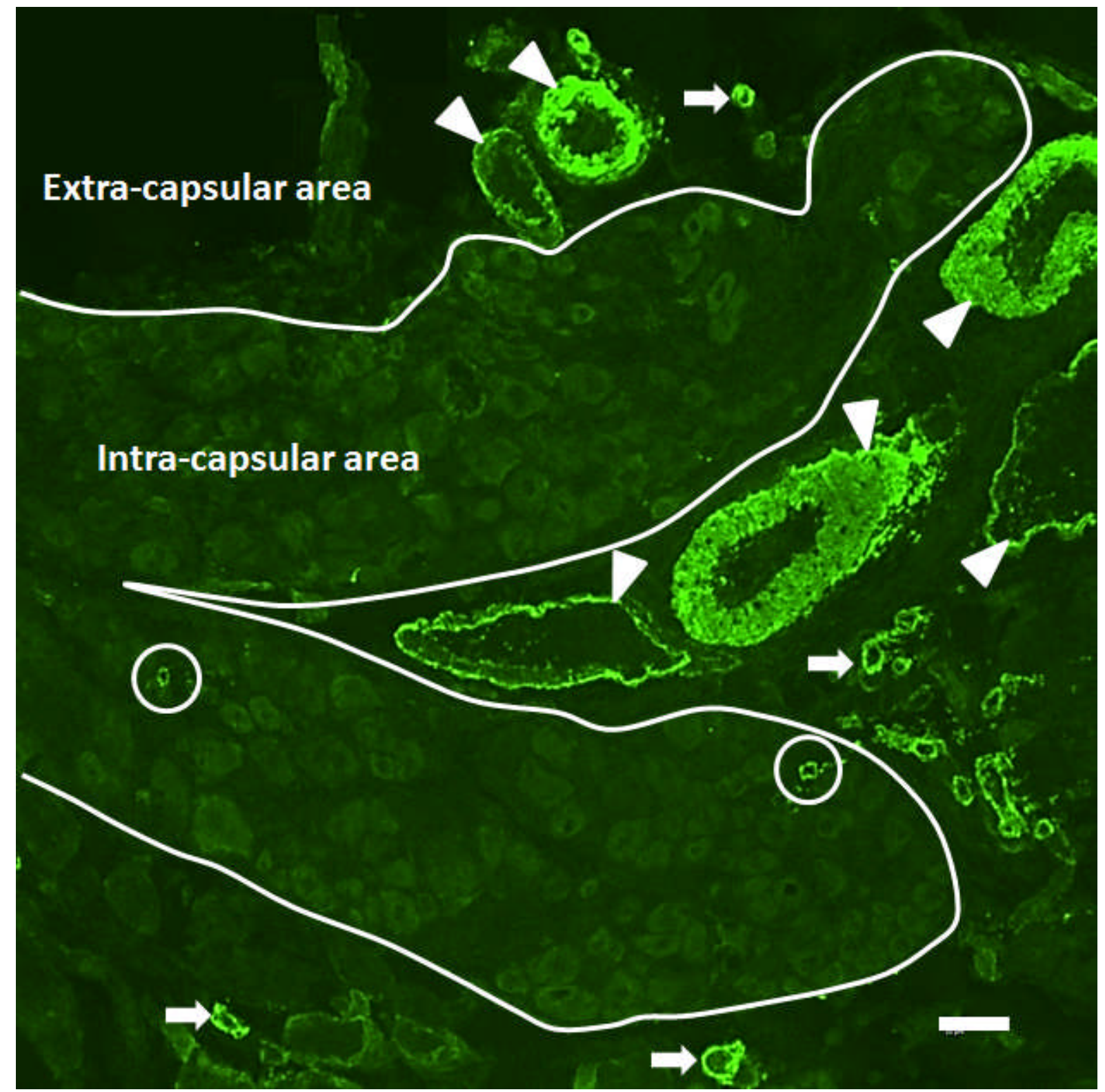


FIGURE 3

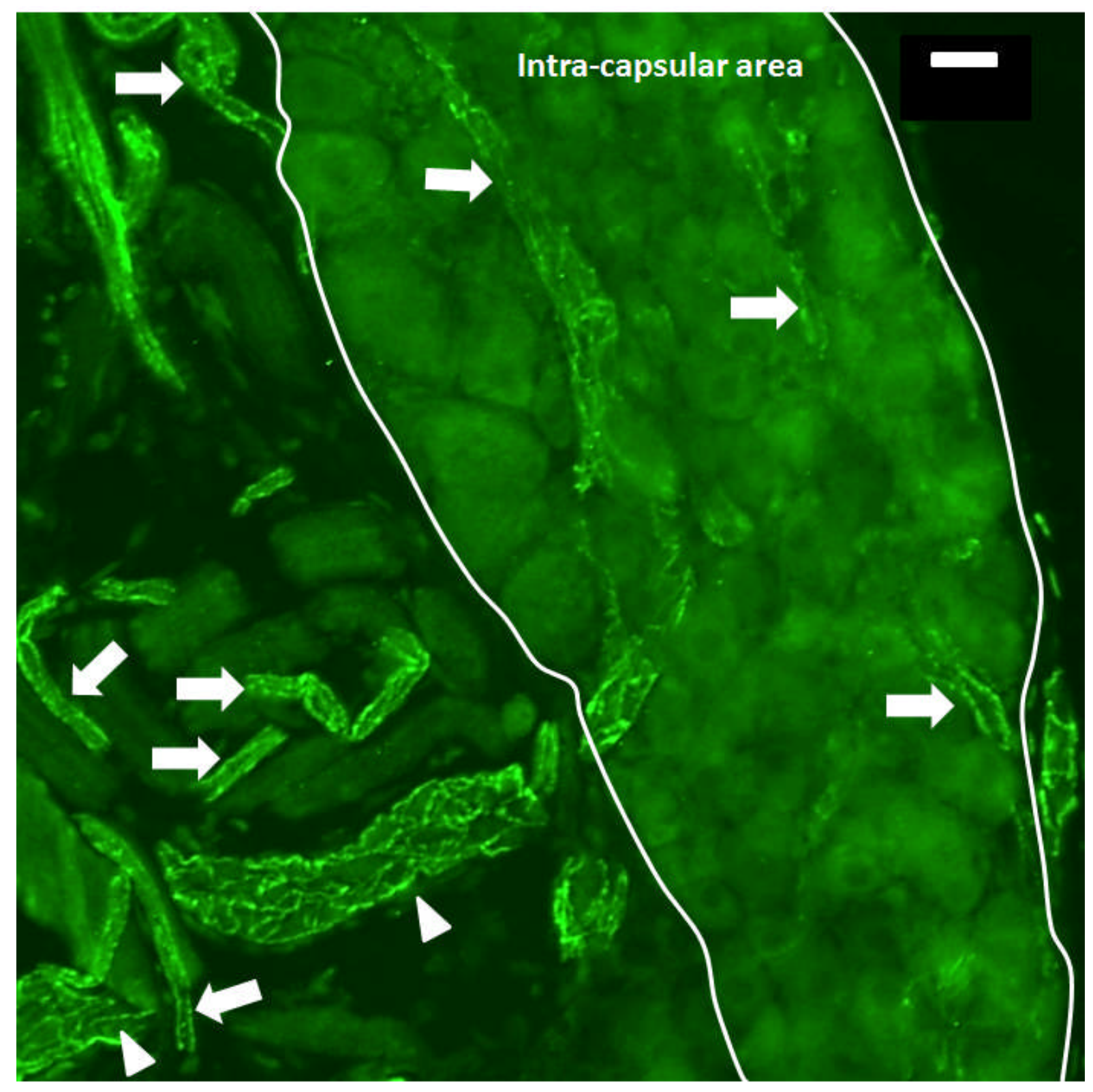


FIGURE 4A

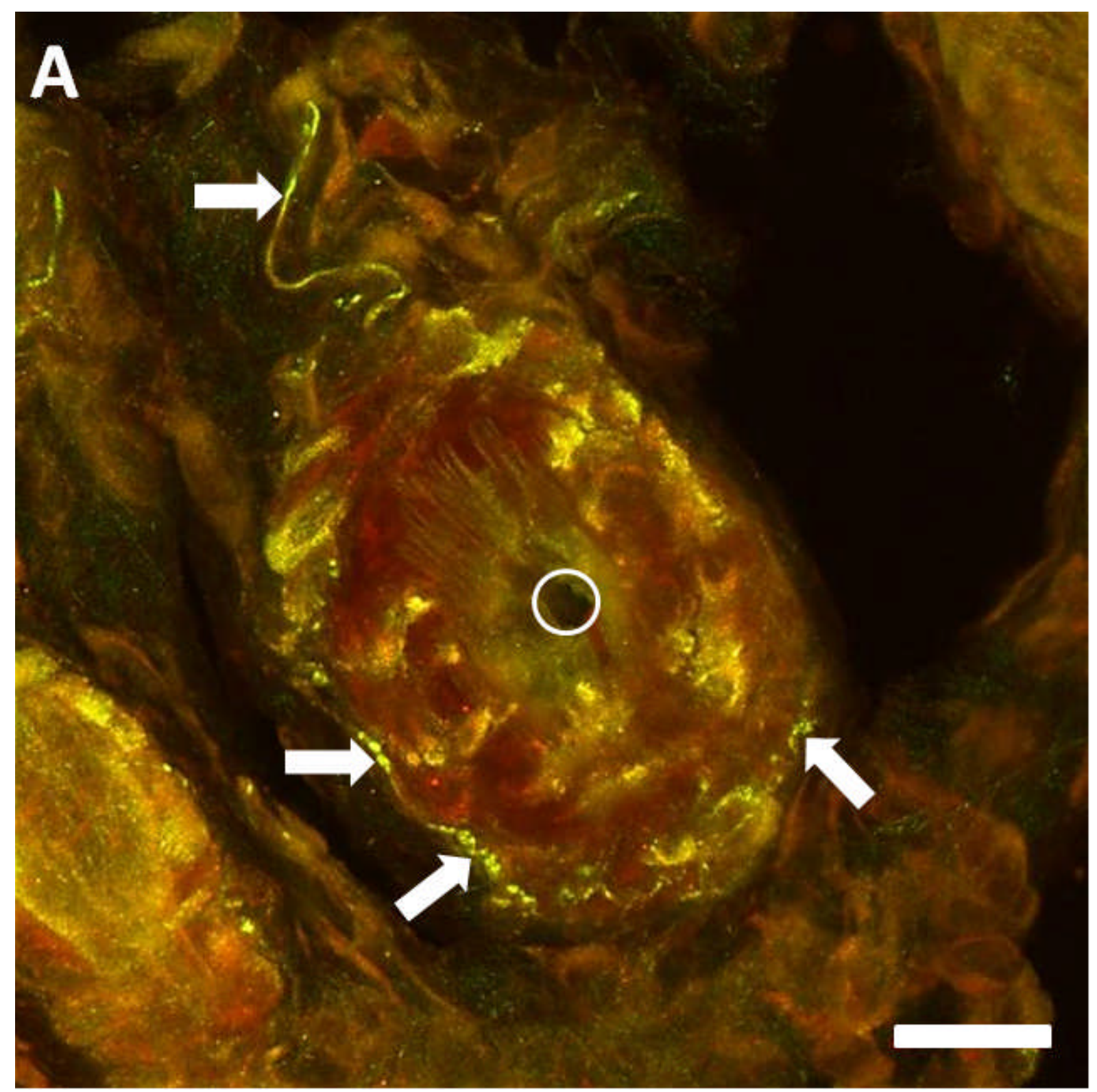


FIGURE 4B

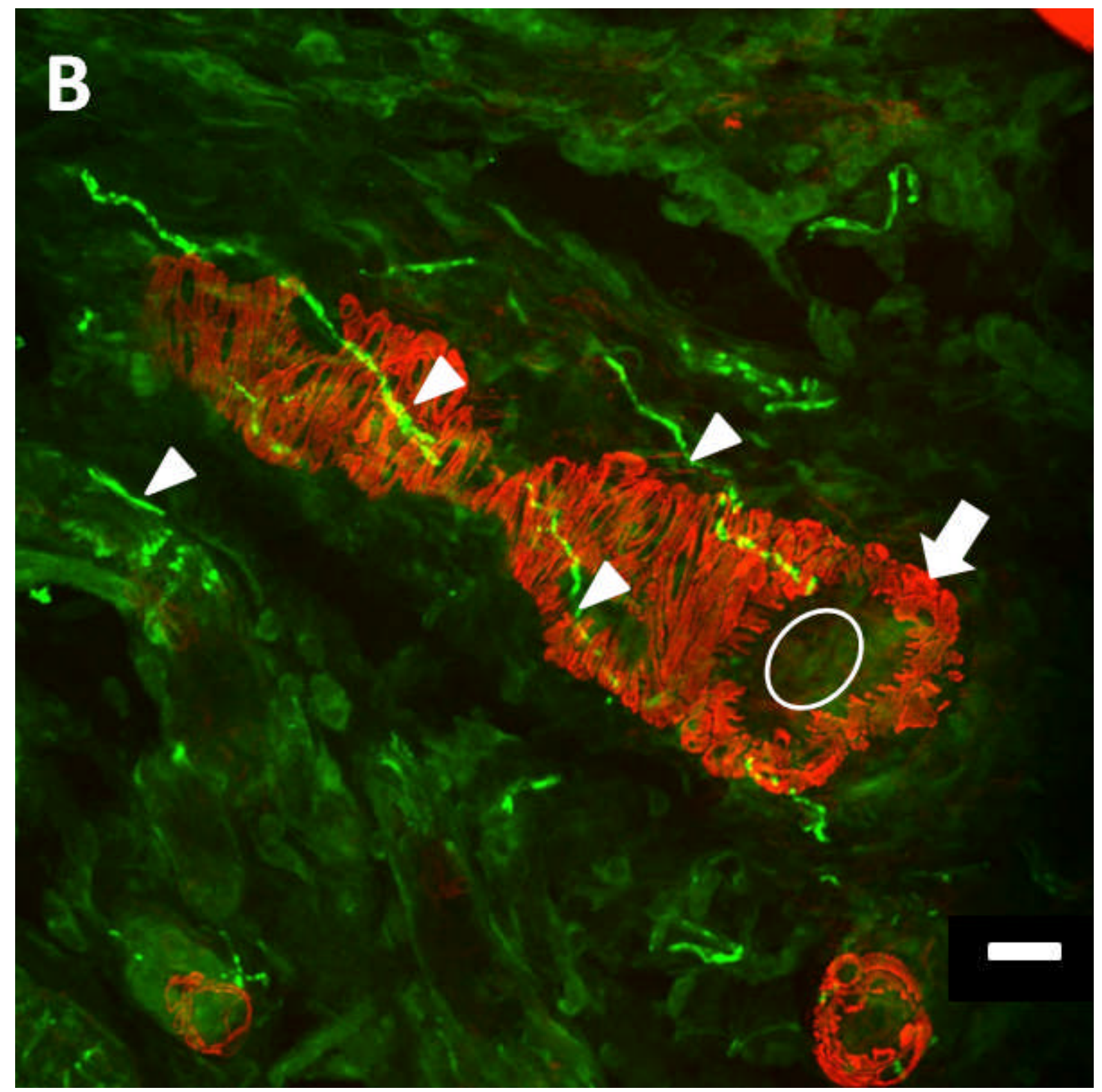


FIGURE 5

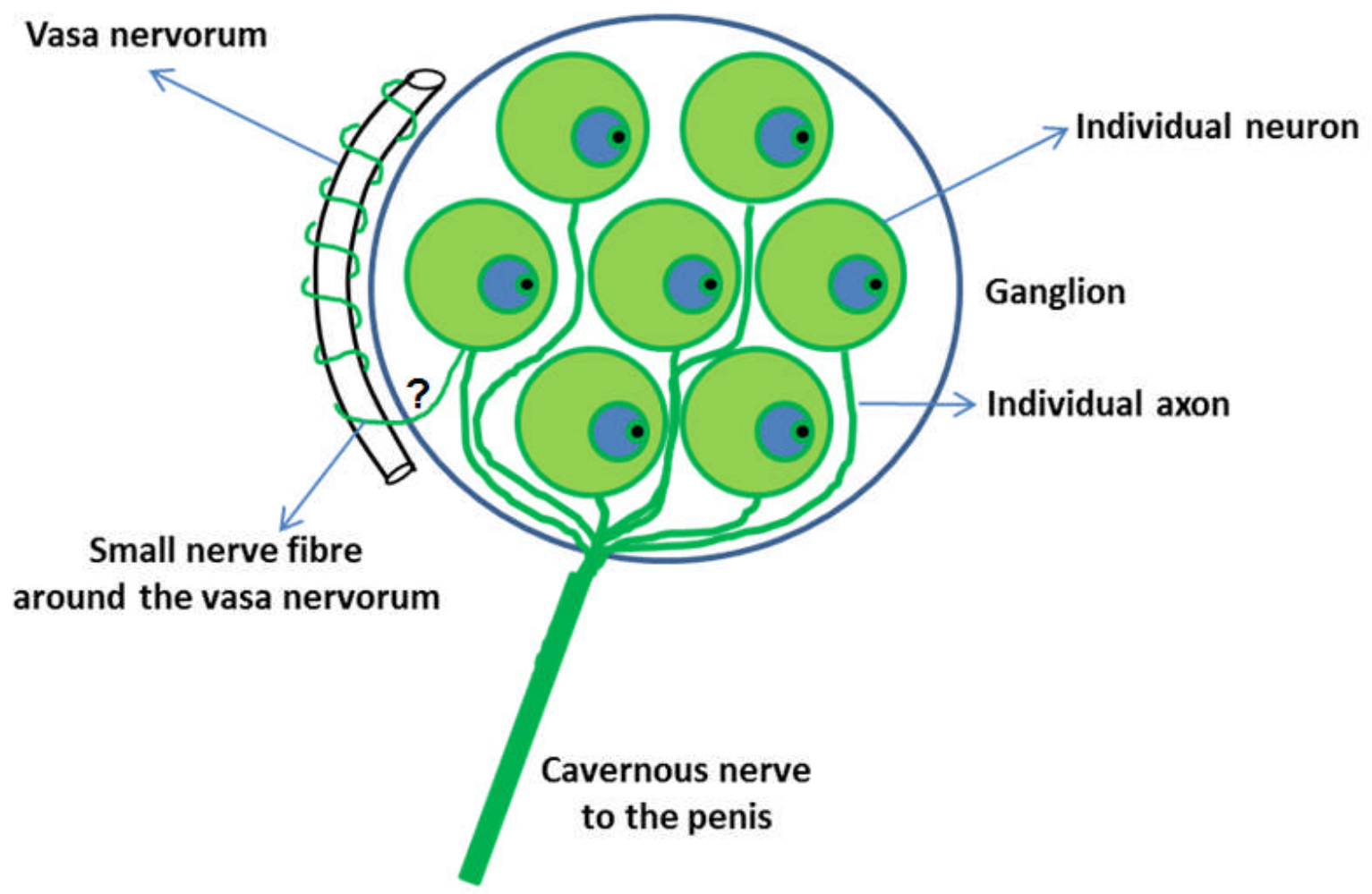


2013-09-12

Vasa Nervorum in rat major pelvic ganglion are innervated by nitrergic nerve fibers

\section{Beetson, Karl A.}

Wiley

Beetson, K. A. (2013) Vasa Nervorum in rat major pelvic ganglion are innervated by nitrergic nerve fibers, Vol. 10, Iss. 12, pp. 2967-2974

http://dx.doi.org/10.1111/jsm.12313

Downloaded from Cranfield Library Services E-Repository 